\title{
THE MODEL OF TEMPORARY TEMPERATURE FIELD DURING MULTI-PASS ARC WELD SURFACING. PART I: ANALYTICAL DESCRIPTION
}

\author{
Jerzy Winczek ${ }^{1}$, Grał̇yna Rygat ${ }^{2}$, Tomasz Skrzypczak ${ }^{1}$ \\ ${ }^{I}$ Faculty of Mechanical Engineering and Computer Science, Czestochowa University of Technology \\ Czestochowa, Poland \\ ${ }^{2}$ Pedagogical Faculty, Jan Dlugosz University in Czestochowa, Poland \\ winczek@gmail.com,g.rygal@ajd.czest.pl,skrzyp@imipkm.pcz.czest.pl
}

\begin{abstract}
This work presents a model of a temperature field in a steel element during multi-pass Gas Metal Arc Weld surfacing taking into account heat of the melted electrode material. An analytical solution for a half-infinite body model is obtained by aggregating temperature increments caused by applying liquid metal and heat radiation of a moving electrode. The assumptions are Gaussian distributed heat sources of applied melted electrode material and of an electric arc.
\end{abstract}

Keywords: temperature field, Gas Metal Arc Weld surfacing, modelling

\section{Introduction}

The basis for welding processes and laser heat processing is the usage of a concentrated moving heat source, which causes temperature field to be changed in time and space. Two approaches dominate in temperature field modeling of these processes. The first approach is numerical, in which the finite difference methods, infinitesimal heat balances and FEM are commonly used [1-7]. The second approach consists of an analytical solution, described further in this work, in which integral transformations and the Green's function method are used frequently. With regard to the common multiple-welding, temperature field models are based on the finite element method [8-13], however, there is lack of analytical solutions.

Modeling of temperature field caused by moving heat source (during welding) was initiated in the middle of the last century by Rosenthal's [14] and Rykalin's [15] works, which assumed point and linear model of heat source. Eagar and Tsai [16] modified Rosenthal's model including 2D Gaussian distributed heat source and developed the solution to a travelling heat source in a semi-infinite steel plate. The model of double ellipsoidal, three-dimensional heat source was first introduced by Goldak et al. [1]. Since then many researchers have tried to determine the temperature field closest to real distribution using analytical methods [17-21]. 
Analytical solution to heat conduction equation offers a quick assessment of temperature field and its dependence on parameters such as e.g. heat source velocity and its power. This method is still very popular in the description of a temperature field.

In most cases of existing solutions of the temperature field only direct effects of electric arc heat on the material of welded or surfaced object are taken into account. Part of the heat generated by the electric arc is consumed to melt the electrode or the additional material, and then transferred to the welded object. The division of the whole heat generated by the electric arc in the modelling of the temperature field is encountered in the literature. $\mathrm{Wu}$ and Sun [22] for large deformations of the weld pool and the weld itself have suggested a model based on the bimodal heat distribution of an electric arc in GMA (Gas Metal Arc) welding. Jeong and Cho [23] have proposed taking into account the area of melted metal in fillet weld by summing up bivariate Gaussian distributed heat source. Analogically, Kang and Cho [24] solved the temperature field in the welding model using the GTA (Gas Tungsten Arc) method taking into consideration filler wire. In solution, the total amount of heat supplied to the base material is specified by adding up the heat of electric arc in the form of flat Gaussian source and point heat source of melted filler wire.

Surfacing by welding is distinguished by applying liquid metal (in some cases up to 20 millimeters thick), which spills across the surface and constitutes additional heat source. Analyses of metallographic specimens of surfaced elements [25] indicate that fusion lines have more irregular shapes than in the case of welding due to liquid metal spilling across the surface of welded element. The necessity of taking into consideration the heat of melted metal in temperature field solutions in welding processes is therefore essential, which is presented in this work.

\section{The analytical description of the temperature field during multi-pass surfacing}

The proposed model assumes physically one heat source - an electric arc, and the heat transfer to the surfaced object is divided into the heat transferred directly through the electric arc and through the melted material of electrode in the form of drops that under the influence of electromagnetic forces are detached and transferred to the forming weld. This material, after mixing in the weld pool, along with the melted material of the object, constitutes the weld. It is assumed that the volume of weld reinforcement is approximately equal to the volume of melted electrode wire, and the amount of heat consumed for melting the electrode equal for the amount of heat accumulated in the reinforcement of the weld pad. It allows the formulation of the temperature field formula:

$$
T(x, y, z, t)-T_{0}=\Delta T_{a}(x, y, z, t)+\Delta T_{w}(x, y, z, t),
$$


where $\Delta T_{a}(x, y, z, t)$ and $\Delta T_{w}(x, y, z, t)$ are temperature accruals caused by the direct impact of electric arc heat and the heat of weld reinforcement (used for fusion of electrode) respectively.

Based on the solution of temperature field for the following heat sources: point [26], surface [27] and volumetric [28], temperature field during single pass surfacing is described [29], where numerical simulation results are confirmed experimentally by other authors [25] (Fig. 1).

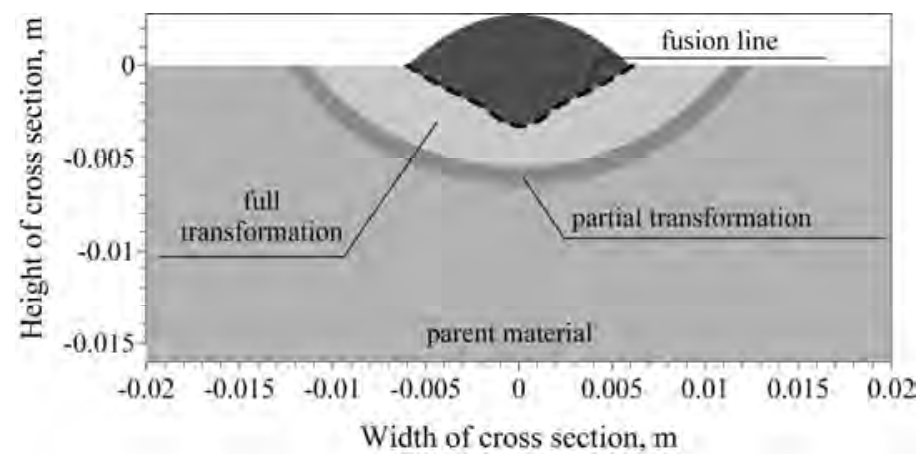

Fig. 1. Heat affected zone: dashed line - fusion line obtained experimentally

In the modelling of temperature field during multi-pass surfacing by welding, one has to take into account changes of temperature caused by the application of consecutive welds (temperature increases with successive passages of the electrode as well as the cooling of already applied welds and areas previously heated), including the overlapping of melted areas (overlaps). Then the temperature field during the application of the $k$-th weld is described by the relationship (Fig. 2):

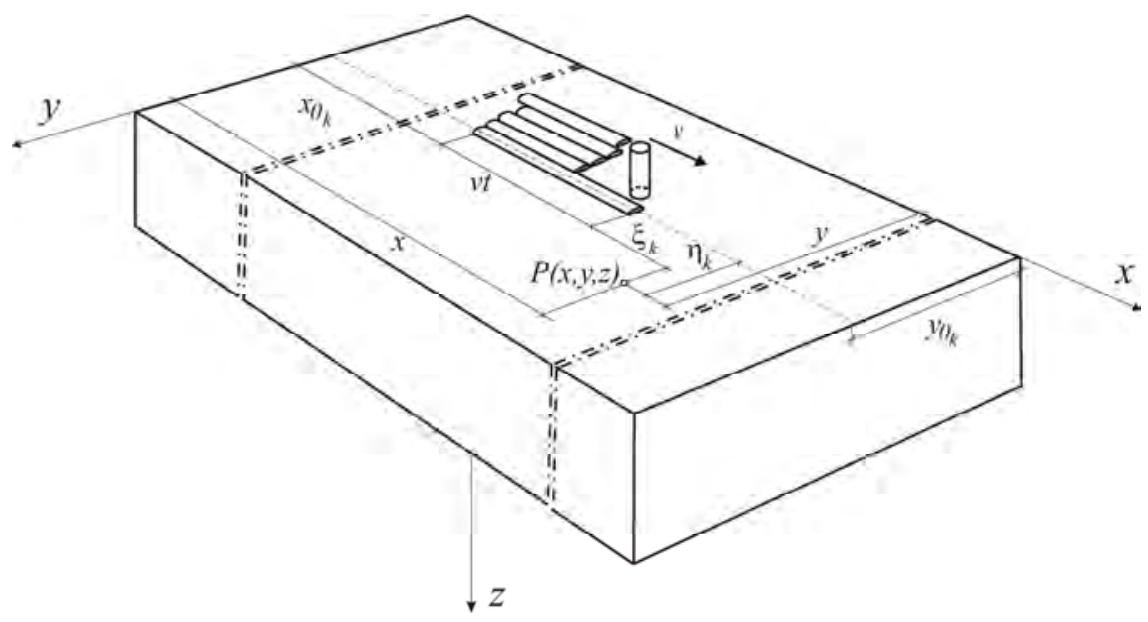

Fig. 2. Scheme for determining temporary distance between the selected point of object and heat source 


$$
T(x, y, z, t)-T_{0}=\sum_{j=1}^{k-1} \Delta T_{j}^{C}+\Delta T_{k}^{H},
$$

where $\Delta T_{j}^{C}$ denotes temperature increase caused by already applied (cooling down) $j$-th weld, while $\Delta T_{j}^{H}$ temperature increase during application of the $k$-th weld. In contrast, the temperature field after application of all welds is equal to:

$$
T(x, y, z, t)-T_{0}=\sum_{j=1}^{k} \Delta T_{j}^{C},
$$

where:

$$
\begin{aligned}
\Delta T_{k}^{H} & =\sum_{i=1}^{2} A_{i}^{H} \int_{t_{b k}}^{t} F_{i}^{H}\left(t^{\prime \prime}\right) d t^{\prime \prime}, \\
\Delta T_{j}^{C} & =\sum_{i=1}^{2} A_{i}^{C} \int_{t_{b j}}^{t_{e j}} F_{i}^{C}\left(t^{\prime}\right) d t^{\prime},
\end{aligned}
$$

(index $i=1$ refers to temperature increase caused by the heat transferred to the weld through droplets of melted electrode material, while $i=2$ refers to temperature increase caused by direct radiation of the electric arc),

$$
\begin{gathered}
A_{i}^{H}=\frac{3}{8} \frac{\dot{q}_{i}}{C_{p} \rho \pi a z_{0 i}} \exp \left(-\frac{v \xi}{2 a}-\frac{v^{2} t_{0 i}}{4 a}\right), \\
F_{H}\left(t^{\prime \prime}\right)=\frac{1}{t^{\prime \prime}+t_{0 i}} \exp \left(-\frac{\xi_{k}^{2}+\eta_{k}^{2}}{4 a\left(t^{\prime \prime}+t_{0 i}\right)}-\frac{v^{2} t^{\prime \prime}}{4 a}\right) \\
\left\{\left(1-\frac{z^{2}+2 a t^{\prime \prime}}{z_{0 i}^{2}}\right) \operatorname{erf}\left(\frac{z+z_{0 i}}{2\left(a t^{\prime \prime}\right)^{0.5}}-\Phi(z) \operatorname{erf}\left(\Phi(z) \frac{z-z_{0 i}}{2\left(a t^{\prime \prime}\right)^{0.5}}\right)\right)+\right. \\
\left.\frac{4 a t^{\prime \prime}}{z_{0 i}^{2}}\left(\frac{z+z_{0 i}}{\left(4 \pi a t^{\prime \prime}\right)^{0.5}} \exp \left(-\frac{\left(z-z_{0 i}\right)^{2}}{4 a t^{\prime \prime}}\right)-\frac{z-z_{0 i}}{\left(4 \pi a t^{\prime \prime}\right)^{0.5}} \exp \left(-\frac{\left(z+z_{0 i}\right)^{2}}{4 a t^{\prime \prime}}\right)\right)\right\} \\
A_{i}^{C}=\frac{3 \dot{q}_{i}}{8 C_{p} \rho \pi a z_{0 i}}, \\
\Phi(z)=\left\{\begin{array}{c}
-1 \text { for } z \in<0, z_{0 i}> \\
1 \text { for } z \in\left(z_{0 i}, \infty\right)
\end{array}\right.
\end{gathered}
$$




$$
\begin{gathered}
F_{C}\left(t^{\prime}\right)=\frac{1}{t+t_{0 i}-t^{\prime}} \exp \left(-\frac{\left(x-v t^{\prime}-x_{0}\right)^{2}+\left(y-y_{0}\right)^{2}}{4 a\left(t+t_{0 i}-t^{\prime}\right)}\right) \\
\left\{\left(1-\frac{z^{2}+2 a\left(t-t^{\prime}\right)}{z_{0 i}^{2}}\right)\left(\operatorname{erf}\left(\frac{z+z_{0 i}}{2\left(a\left(t-t^{\prime}\right)\right)^{0.5}}\right)-\Phi(z) \operatorname{erf}\left(\Phi(z) \frac{z-z_{0 i}}{2\left(a\left(t-t^{\prime}\right)\right)^{0.5}}\right)\right)+\right. \\
\left.\frac{4 a\left(t-t^{\prime}\right)}{z_{0 i}^{2}}\left(\frac{z+z_{0 i}}{\left(4 \pi a\left(t-t^{\prime}\right)\right)^{0.5}} \exp \left(-\frac{\left(z-z_{0 i}\right)^{2}}{4 a\left(t-t^{\prime}\right)}\right)-\frac{z-z_{0 i}}{\left(4 \pi a\left(t-t^{\prime}\right)\right)^{0.5}} \exp \left(-\frac{\left(z+z_{0 i}\right)^{2}}{4 a\left(t-t^{\prime}\right)}\right)\right)\right\} \\
\xi_{k}=x-v\left(t-(k-1)\left(\frac{l_{k}}{v}+t_{p k}\right)\right)-x_{0 k 1}, \\
\eta_{k}=y-y_{0 k}, \\
\dot{q}_{2}=\kappa U I-\dot{q}_{1},
\end{gathered}
$$

$a$ - thermal diffusivity $\left[\mathrm{m}^{2} / \mathrm{s}\right], C_{p}$ - specific heat $[\mathrm{J} / \mathrm{kg} \mathrm{K}], \rho-$ density $\left[\mathrm{kg} / \mathrm{m}^{3}\right]$, $z_{0 i}[\mathrm{~m}]$ denotes depth of heat source deposition, $y_{0 k}$ - coordinate of $k$-th weld axis, quantity $t_{0 i}[\mathrm{~s}]$ characterizes the surface heat distribution, so that:

$$
r_{i}^{2}=4 a t_{0 i},
$$

where $r_{i}$ denotes averaged radius of Gaussian distributed heat source [30], $U$ [V], $I[\mathrm{~A}]$ and $\kappa$ are voltage, amperage and arc efficiency respectively, $v[\mathrm{~m} / \mathrm{s}]$ - welding velocity (of electrode); while $t_{b j}[\mathrm{~s}]$ and $t_{e j}[\mathrm{~s}]$ - denote starting and finishing time of applying the $j$-th weld defined as:

$$
\begin{aligned}
t_{b j} & =(j-1)\left(l_{j} / v+t_{p j}\right), \\
t_{e j} & =(j-1) t_{p j}+j l_{j} / v,
\end{aligned}
$$

$l_{j}[\mathrm{~m}]$ - the length of the $j$-th weld with coordinates $x_{0 j}$ and $x_{k j}$

$$
l_{j}=x_{k j}-x_{0 j},
$$

$t_{p i}[\mathrm{~s}]$ - auxiliary and complementary time associated with idle motion of electrode or with other operations resulting from the needs of manufacturing process (e.g. correction or change of technological parameters) prior to application of the $j$-th weld.

The total amount of heat $q_{l}$ contained in the material of melted electrode is expressed by relationship [31]:

$$
q_{1}=\Delta q_{\text {solid }}+\Delta q_{f}+\Delta q_{\text {liqiud }},
$$


where $\Delta q_{\text {solid }}$ - the heat necessary to heat up the electrode from initial temperature to melting temperature:

$$
\Delta q_{\text {solid }}=m C_{p}\left(T_{S}-T_{e}\right),
$$

$\Delta q_{f}$ - heat used for melting the electrode (heat of fusion):

$$
\Delta q_{f}=m L,
$$

$\Delta q_{\text {liquid }}$ - heat used for heating up melted material to the temperature, in which the drop of metal falls on the surface of welded material:

$$
\Delta q_{\text {liquid }}=m C_{p}\left(T_{L}-T_{S}\right) .
$$

Then Eq. (18) takes the form:

$$
q_{1}=m C_{p}\left(T_{S}-T_{e}\right)+m C_{p}\left(T_{L}-T_{S}\right)+m L,
$$

where: $T_{e}$ - the initial temperature of electrode (the temperature of the contact tip with the welding head) [31].

Thus, differentiating the equation (22) with respect to time, $\dot{q}_{1}$ appearing in equations (6) and (8), is defined by the relationship:

$$
\dot{q}_{1}=\dot{m}\left(C_{p}\left(T_{L}-T_{e}\right)+L\right)
$$

where $\dot{m}$ and $m$ occurring in equations (19)-(23) are equal:

$$
\dot{m}=\rho_{e} \frac{\pi d^{2}}{4} v_{e},
$$

$v_{e}[\mathrm{~m} / \mathrm{s}]$ - velocity of passing electrode wire with diameter $d[\mathrm{~m}]$, density $\rho_{e}$ $\left[\mathrm{kg} / \mathrm{m}^{3}\right], T_{L}[\mathrm{~K}]$ - temperature at which metal leaves the wire tip, $L[\mathrm{~J} / \mathrm{kg}]$ - latent heat of fusion and $T_{S}[\mathrm{~K}]$ - solidus temperature.

\section{Conclusions}

Arc weld surfacing is distinguished by the application of liquid metal, which spills across the surface and creates additional heat source. Consideration of this heat source is therefore essential in temperature field solutions. In this work a temperature field description of multi-pass surfacing for half-infinite body model is presented. Point of departure for the description of this model is the solution of heat conduction equation for a single weld. In the proposed model the heat of an electric arc transferred to surfaced object is divided into the heat conducted 
directly through thermal radiation from a moving electrode and the heat of melted material of the electrode in the form of drops which under the influence of electromagnetic forces are detached and fall on the weld. As a comparative criterion of numerical simulations of single-pass surfacing and experimental research, results are assumed the shape and measurements of the fusion line. The accuracy of solution is confirmed by comparison of the calculated fusion line with that obtained experimentally by other authors with the same technological parameters of the process.

\section{References}

[1] Goldak J., Chakravarti A., Bibby A., A new finite element model for welding heat sources, Metallurgical Transactions 1984, 15B, 299-305.

[2] Komanduri R., Hou Z.B., Thermal analysis of the arc welding process: Part I. General solutions, Metall. Mater. Trans. 2000, 31B, 1353-1370.

[3] Kumar A., Debroy T., Heat transfer and fluid flow during gas-metal-arc fillet welding for various joint configurations and welding positions, Metall. Mater. Trans. 2007, 38A, 506-519.

[4] Mahapatra M.M., Datta G.L., Pradhan B., Three-dimensional finite element analysis to predict the effects of shielded metal arc welding process parameters on temperature distributions and weldment zones in butt and one-sided fillet welds, Proc. I. Mech. E. Part B: J. Eng. Manuf. 2006, 220, 837-845.

[5] Piekarska W., Kubiak M., Saternus Z., Numerical modelling of thermal and structural strain in laser welding process, Archiv. Metall. Materials 2012, 57, 1219-1227.

[6] Kulawik A., Modeling of thermomechanical phenomena of welding process of steel pipe, Archiv. Metall. Materials 1012, 57, 1229-1238.

[7] Fu G., Lourenco M.I., Duan M., Estefen S.F., Effect of boundary conditions on residual stress and distortion in T-joint welds, J. Constructional Steel Research 2014, 102, 121-135.

[8] Börjesson L., Lindgren L.E., Simulation of multipass welding with simultaneous computation of material properties, Trans. ASME 2001, 123, 106-111.

[9] Jiang W., Yahiaoui K., Hall F.R., Finite element predictions of temperature distributions in a multipass welded piping branch junction, J. Press. Vessel Technol. 2005, 127, 7-12.

[10] Deng D., Murakawa H., Numerical simulation of temperature field and residual stress in multipass welds in stainless steel pipe and comparison with experimental measurements, Comput. Mat. Sci. 2006, 37, 269-277.

[11] Heinze C., Schwenk C., Rethmeier M., Numerical calculation of residual stress development of multi-pass gas metal arc welding under high restraint conditions, Mat. Design 2012, 35, 201-209.

[12] Pathak C.S., Navale L.G., Sahasrabudhe A.D., Rathod M.J., Analysis of thermal cycle during multipass arc welding, Welding J. 2012, 91, 149-154.

[13] Joshi S., Hildebrand J., Aloraier A.S., Rabczuk T., Characterization of material properties and heat source parameters in welding simulation of two overlapping beads on a substrate plate, Comput. Mat. Sci. 2013, 69, 559-565.

[14] Rosenthal D., Mathematical theory of heat distribution during welding and cutting, Welding J. 1941, 20, 220-234.

[15] Rykalin N.N., Thermal basics of welding, AN SSSR, Moskva 1947 (in Russian).

[16] Eagar T.W., Tsai N.S., Temperature fields produced by traveling distributed heat sources, Welding J. 1983, 62, 346-355. 
[17] Bo K.S., Cho H.S., Transient temperature distribution in arc welding of finite thickness plates, Proc. Inst. Mech. Eng. 1990, 204 B3, 175-183.

[18] Jeong S.K., Cho H.S., An analytical solution to predict the transient temperature distribution in fillet arc welds, Welding J. 1997, 76, 223-232.

[19] Nguyen N.T., Ohta A., Matsuoka K., Suzuki N., Maeda Y., Analytical solutions for transient temperature of semi-infinite body subjected to 3-D moving heat sources, Welding J. 1999, 78, 265-274.

[20] Nguyen N.T., Mai Y.W., Simpson S., Ohta A., Analytical approximate solution for double ellipsoidal heat source in finite thick plate, Welding J. 2004, 84, 82-93.

[21] Kwon Y., Weckman D.C., Analytical thermal model of conduction mode double sided arc welding, Sci. Technol. Weld. Joining 2008, 13, 539-549.

[22] Wu C.S., Sun J.S., Modelling the arc heat flux distribution in GMA welding, Comput. Mat. Sci. 1998, 9, 397-402.

[23] Jeong S.K., Cho H.S., An analytical solution for transient temperature distribution in fillet arc welding including the effect of molten metal, Proc. Inst. Mech. Egrs 1997, 211, 63-72.

[24] Kang S.F., Cho H.S., Analytical solution for transient temperature distribution in gas tungsten arc welding with consideration of filler wire, Proc. Instsn. Engrs 1999, 213B, 799-811.

[25] Klimpel A., Balcer M., Klimpel A.S., Rzeźnikiewicz A., The effect of the method and parameters in the GMA surfacing with solid wires on the quality of pudding welds and the content of the base material in the overlay, Welding Int. 2006, 20, 845-850.

[26] Radaj D., Heat Effects of Welding. Temperature Field, Residual Stress, Distortion, Springer-Verlag, Berlin Heidelberg, New York, London, Paris, Tokyo 1992.

[27] Easterling K.E., Modelling the weld thermal cycle and transformation behaviour in the heat affected zone, [in:] Mathematical Modelling of Weld Phenomena, eds. H. Cerjak, K.E. Easterling, The Institute of Materials, London 1993.

[28] Winczek J., Analytical solution to transient temperature field in a half-infinite body caused by moving volumetric heat source, Int. J. Heat Mass Transfer 2010, 53, 5774-5781.

[29] Winczek J., Temperature field in surfaced steel casts with the heat of the weld taken into account, Archiv. Foundry Eng. 2014, 14, Spec. Is. 1/2014, 121-126.

[30] Vishnu P.R., Li W.B., Easterling K.E., Heat-flow model for pulsed welding, Mater. Sci. Technol. 1991, 7, 649-659.

[31] Modenesi P.J., Reis R.I., A model for melting rate phenomena in GMA welding, J. Mater. Proc. Technol. 2007, 189, 199-205. 